\title{
Reduced Water Supply Induces Fall Acclimation of Evergreen Azaleas
}

\author{
Tomasz Anisko' and Orville M. Lindstrom ${ }^{2}$ \\ Department of Horticulture, University of Georgia, Georgia Experiment Station, Griffin, GA 30223
}

Additional index wards. bark split, cold hardiness, water stress

\begin{abstract}
The primary cause of losses in evergreen azaleas injured by early freeze is bark split on lower stems. Delayed acclimation in the fall is thought to permit this injury. We examined whether reduced water supply affects acclimation of Rhododendron L. 'Coral Bell', 'Hinodegiri', and 'Red Ruffle'. Containerized plants were grown under four watering regimes and placed outdoors or in the greenhouse. The water content of the growing medium was maintained at either 0.3 to 0.4 or 0.5 to $0.6 \mathrm{~m}^{3} \cdot \mathrm{m}^{-3}$ from 16 June to $30 \mathrm{Aug}$. 1993, when half of the plants under each of these regimes was switched to the other watering regime. Freeze tests were conducted on 30 Aug. and 9 (let. Injury to leaves, and lower, middle, and upper stems was evaluated visually. Acclimation of leaves and upper stems before the August test, in most cases, was not stimulated by reduced water content, while the response of lower and middle stems was cultivar- and location-specific. The lower water content treatment after 30 Aug. generally increased freeze tolerance of all plant parts regardless of the previous watering regime. The higher water content treatment after 30 Aug. either prevented or delayed acclimation. This study demonstrated that the reduced water supply provided a feasible means of promoting acclimation of evergreen azaleas in late summer.
\end{abstract}

Early freeze, particularly if preceeded by a period of warm and wet weather, can severely injure evergreen azaleas. The primary cause of such injuries is bark split occurring on lower stems, although upper stems can also be affected. The injury is not evident immediately and may remain unnoticed until the following spring, when the plants are water stressed, resulting in foliage discoloration, stem dieback, and plant death (Brooks, 1974; Cook, 1978). Delayed acclimation of evergreen azaleas in the fall is thought to cause bark split injury (Alexander and Havis, 1980a; Flint, 1966). This delayed acclimation is especially manifested in the lower stems, which tend to lag behind upper parts of the plant. Alexander and Havis (1980a) attributed slow rate of lower stem acclimation in evergreen azaleas to a preferential acropetal movement of hypothetical hardiness promoters.

High temperatures in a root zone, common in containerized nursery stock, can further prevent proper acclimation of lower stems. Alexander and Havis (1980b) speculated that lower stems of evergreen azaleas go through two stages of acclimation, the second of which requires a root temperature below $16 \mathrm{C}$. In many areas, particularly the southeastern United States, exposure to acclimating temperatures is inadequate to harden evergreen azaleas sufficiently before the first freeze.

Low temperature in a root zone reduces water uptake by roots (Kramer, 1983). Decreased root conductivity was observed in red osier dogwood during cold acclimation (McKenzie et al., 1974; Parsons, 1978). It has been recognized that restricting water supply can increase cold hardiness in woody plants even under nonhardening temperature conditions. Yelenosky (1979) demonstrated that acclimation induced by water stress and low temperature resulted in similar cold hardiness of young citrus trees. Chen et al. $(1975,1977)$ found that cold hardiness of stems of red osier dogwood plants could be increased by water stress. Cold hardiness in several species of herbaceous plants was also induced by

Received for publication 17 June 1994. Accepted for publication 22 Nov. 1994. Authors' sincere thanks go to Tom Dodd Nurseries, Semmes, Ala., and to McCorkle Nurseries, Dearing, Ga. for providing plant material for this study. The cost of publishing this paper was defrayed in part by the payment of page charges, Under postal regulations, this paper therefore must be hereby marked advertisement solely to indicate this fact.

'Graduate research assistant.

${ }^{2}$ Associate professor. imposing water stress (Burrows et al., 1989; Cloutier and Siminovitch, 1982; Cox and Levitt, 1976; Thomas and James, 1993).

Measures to prevent bark split of azaleas include fall applications of growth retardants (Norcini and Aldrich, 1990). However, this treatment suppresses initial spring growth and delays flowering. Since watering azaleas is universally practiced by nursery growers, reducing or even withholding irrigation is the easiest cultural manipulation available. Therefore, the purpose of this study was to examine whether reduced water supply can induce earlier acclimation of three cultivars of evergreen azaleas.

\section{Materials and Methods}

Commercially grown plants of three cultivars of evergreen azaleas, Rhododendron 'Coral Bell' (CB), 'Hinodegiri' (HD), and 'Red Ruffle' (RR), were used in field and greenhouse studies.

Field study. Four-year-old plants were grown in 9-liter containers placed in the open field. Growing medium contained 1 peat: 1 composted pine bark (v/v). Plants were fertilized $\left(3 \mathrm{~g} \cdot \operatorname{liter}^{-1}\right)$ with Osmocote (18N-2.6P-9.9K, Grace Sierra Horticultural Co., Milpitas, Calif.) once after planting into containers in May.

Greenhouse study. Three-year-old plants were grown in 2.2-liter containers in an unheated greenhouse. The growing medium (Metro Mix 300, Grace Sierra) contained Canadian sphagnum peat, vermiculite, processed bark ash, and washed sand. Plants were fertilized $\left(1 \mathrm{~g} \cdot\right.$ liter $\left.^{-1}\right)$ with Sta-green (11N-5P-5K, Progress Growers Supply, Canton, Ga.) three times between March and June.

Plants in each of the experiments were grown under four different watering regimes. The volumetric water content of the growing medium was maintained at either 0.30 to $0.40 \mathrm{~m}^{3} \cdot \mathrm{m}^{-3}$ (dry) or 0.50 to $0.60 \mathrm{~m}^{3} \cdot \mathrm{m}^{-3}$ (wet) between 16 June and 30 Aug. 1993. Pots were watered when water content of the medium approached lower limits of the intended ranges. Between 30 Aug. and 9 Oct., the previously imposed watering regime remained unchanged or was switched to the other regime, producing dry/dry, dry/wet, wet/wet, and wet/dry watering regimes. In the field study, no attempt was made to exclude natural rainfall; therefore, occasionally water content could exceed intended levels. However, the average intended water content ranges were maintained for each treatment. Volumetric water content of the medium was monitored 
twice a week with a time-domain reflectometry technique described by (Anisko et al., 1994). The method used a cable tester (Tektronix 1502C metallic time domain reflectometer, Tektronix, Beaverton, Ore.) to measure the apparent dielectric permittivity of the growing medium which strongly depended on water content. An empirical relationship between dielectric constant and water content was developed in a form of calibration equation (Anisko et al., 1994). Plants were organized in three randomized complete blocks with eight plants per each block $\times$ cultivar $\times$ watering regime. A randomly selected pot in each block $\times$ cultivar $\times$ watering regime was used for monitoring volumetric water content. Mean air temperature was calculated based on average of minimum and maximum temperature for each sunup to sunup day.

Cold hardiness of plants was evaluated in the laboratory with freeze-tolerance tests on leaves and stems. Stem sections $\approx 4$ to 5 $\mathrm{cm}$ long were sampled in the morning from three locations on a plant: lower stems were the most basal stems up to $4 \mathrm{~cm}$ from the roots, upper stems were the current season's growth leafy stems, and middle stems were leafless stems of the intermediate position. The freezing tolerance tests were performed on 30 Aug. and 9 Oct.. Samples were wrapped in moist cheesecloth, placed in test tubes, and inserted in a freezing bath (Forma Scientific, Marietta, Ohio). Sample temperature was recorded by thermocouples placed next to a stem or leaf. To avoid excessive supercooling of tissue water, when the temperature of the samples stabilized at $-2.0 \pm 0.5 \mathrm{C}$, the samples were inoculated with ice crystals. Following freezing of the samples, the temperature was lowered at the rate of $4 \mathrm{C}$ per hour. After retaining the selected temperature $(-2$ to $-12 \mathrm{C}$ at 2-degree intervals) for $1 \mathrm{~h}$, samples were removed from the bath and thawed in the refrigerator at $2.0 \pm 0.5 \mathrm{C}$. Control samples were kept on ice for the duration of the test. To evaluate injury, thawed samples were placed in polyethylene bags for 7 days and incubated at room temperature. Freezing injury was evaluated visually with oxidative browning of injured tissues as the criterion and rated on a scale of $0=$ no browning, $1=$ browning light or in small areas, $2=$ browning darker or in larger areas, and $3=$ all sample dark brown. The Richards function fitting to the rating values was performed by modified Gauss-Newton method using NLIN procedure of SAS (SAS Institute, 1985). The inflection point of the Richards function was used as an estimate of the lethal temperature (von Firks and Verwijst, 1993).

\section{Results}

Field study. Field plants were exposed to lower temperatures compared to the greenhouse plants for the duration of the experiment (Table 1). This factor, in addition to the natural rainfall and larger container size, may account for relatively higher water content of the growing medium of the dry watering regimes in the field study than in the greenhouse study. Nevertheless, before 30 Aug. lower and middle stems of HD and RR as well as upper stems and leaves of $\mathrm{CB}$ under the dry watering regime acclimated to temperatures $\approx 2 \mathrm{C}$ lower than under the wet watering regime (Figs. $1-3)$.

Continuation of the dry conditions between 30 Aug. and 9 Oct. allowed further acclimation in all plant parts of three cultivars except for leaves of CB. Imposing dry conditions on plants previously grown under the wet watering regime also increased freeze tolerance of most of the plant parts except for middle stems of HD and CB. Leaves of three cultivars and upper stems of CB reached the same level of freeze tolerance by 9 Oct. when grown under dry conditions between 30 Aug. and 9 Oct. regardless of their previous treatment. Lower and middle stems of plants, except for HD lower stems, grown under the dry watering regime after 30 Aug. acclimated to lower temperature if previously maintained under dry conditions than those maintained previously under wet conditions. Imposing wet conditions between 30 Aug. and 9 Oct. either prevented or delayed acclimation in all plant parts of three cultivars, regardless of their previous treatment, compared to dry conditions. In the 9 Oct. freeze test, most plant parts reached similar hardiness as a result of wet conditions between $30 \mathrm{Aug}$. and 9 Oct. regardless of the watering regime before 30 Aug.. However, upper stems and leaves of RR and in lower stems and leaves of HD plants previously under dry conditions acclimated to lower temperature then in plants previously under wet conditions, despite the wet treatment between 30 Aug. and 9 Oct.

Greenhouse study. Only plants of RR tolerated stress imposed by dry watering regime. Plants of CB died or declined severely by 30 Aug., while plants of HB died by 9 Oct., as a result of dry conditions. Plants of RR, except for their lower stems, acclimated to lower temperature under dry watering regime before $30 \mathrm{Aug}$. but were later very prompt to reacclimate when exposed to wet conditions. Continuation of dry condi-

Table 1. Mean air temperature and average volumetric water content for field and greenhouse studies and four watering regimes.

\begin{tabular}{|c|c|c|}
\hline \multirow{2}{*}{$\begin{array}{l}\text { Study and } \\
\text { watering regime }\end{array}$} & \multicolumn{2}{|c|}{ Period } \\
\hline & 16 June-30 Aug. & 31 Aug. -9 Oct. \\
\hline \multicolumn{3}{|l|}{ A) Field study } \\
\hline Mean air temperature $\left[{ }^{\circ} \mathrm{C}\right]$ & 23.1 & 18.0 \\
\hline \multicolumn{3}{|c|}{ Volumetric water content $\left[\mathrm{m}^{3} \cdot \mathrm{m}^{-3}\right]$ (average $\left.\pm \mathrm{SD}\right)$} \\
\hline Wet/wet & $0.51 \pm 0.05$ & $0.55 \pm 0.06$ \\
\hline Wet/dry & $0.51 \pm 0.05$ & $0.41 \pm 0.04$ \\
\hline Dry/wet & $0.40 \pm 0.03$ & $0.53 \pm 0.05$ \\
\hline Dry/dry & $0.39 \pm 0.03$ & $0.39 \pm 0.05$ \\
\hline \multicolumn{3}{|l|}{ B) Greenhouse study } \\
\hline Mean air temperature $\left[{ }^{\circ} \mathrm{C}\right]$ & 29.5 & 25.5 \\
\hline \multicolumn{3}{|c|}{ Volumetric water content $\left[\mathrm{m}^{3} \mathrm{~m}^{-3}\right]$ (average $\pm \mathrm{SD}$ ) } \\
\hline Wet/wet & $0.53 \pm 0.05$ & $0.59 \pm 0.04$ \\
\hline Wet/dry & $0.52 \pm 0.05$ & $0.34 \pm 0.01$ \\
\hline Dry/wet & $0.34 \pm 0.02$ & $0.58 \pm 0.04$ \\
\hline Dry/dry & $0.35 \pm 0.02$ & $0.36 \pm 0.03$ \\
\hline
\end{tabular}



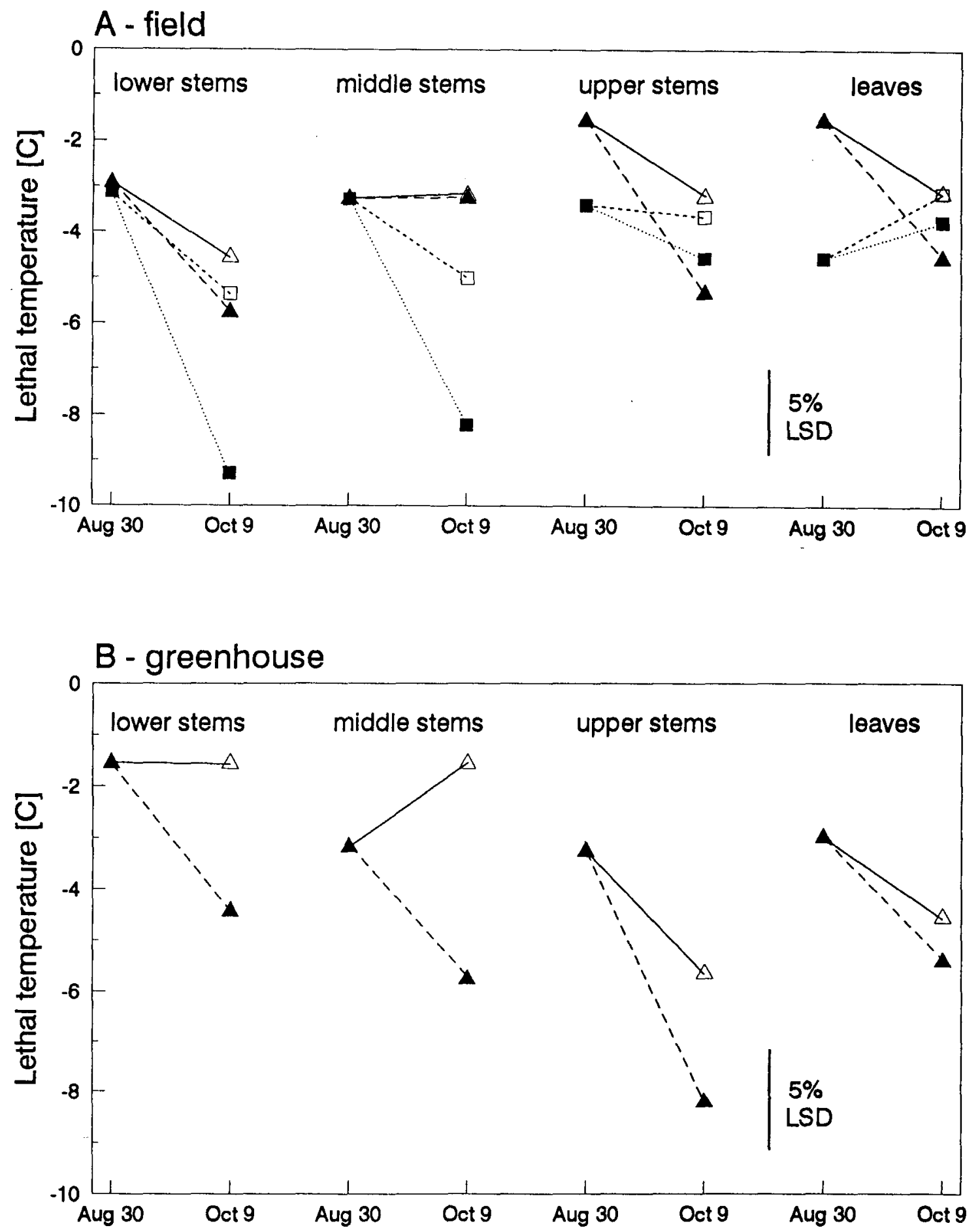

Fig. 1. Lethal temperature for leaves, lower, middle, and upper stems of Rhododendron 'Coral Bell' plants grown under dry/dry ( $\mathbf{\square}$ ), dry/wet ( $\square$ ), wet/dry $(\boldsymbol{\Delta})$, and wet/wet $(\Delta)$ watering regimes in the field $(\mathbf{A})$ and greenhouse (B) study on 30 Aug. and 9 Oct..

tions stimulated further acclimation in leaves and upper stems of RR, but not in lower and middle stems. By 9 Oct., plants of RR under dry watering regime reached similar level of hardiness regardless of their treatment before 30 Aug., except for lower stems which acclimated to lower temperature if previously grown under wet conditions. Continuation of wet watering regime after 30 Aug. either prevented or delayed acclimation of all plant parts of RR and CB and in lower stems of HD compared to plants exposed to dry conditions. Leaves and middle and upper stems of HD acclimated at the same rate, irrespective of watering. Imposing dry conditions after 30 Aug. generally enhanced acclimation in all plant parts of three cultivars except for lower and middle stems of previously stressed plants of RR.

\section{Discussion}

Acclimation of upper plant parts (leaves and upper stems), in most cases, was not stimulated by reducing water supply between 16 June and 30 Aug. Response of lower plant parts (lower and middle stems) to water stress at that time was cultivar and location (greenhouse or field) specific. Water stress under field conditions promoted early acclimation of RR and $\mathrm{HD}$, but not of $\mathrm{CB}$. Interestingly, $\mathrm{CB}$ plants were also the 

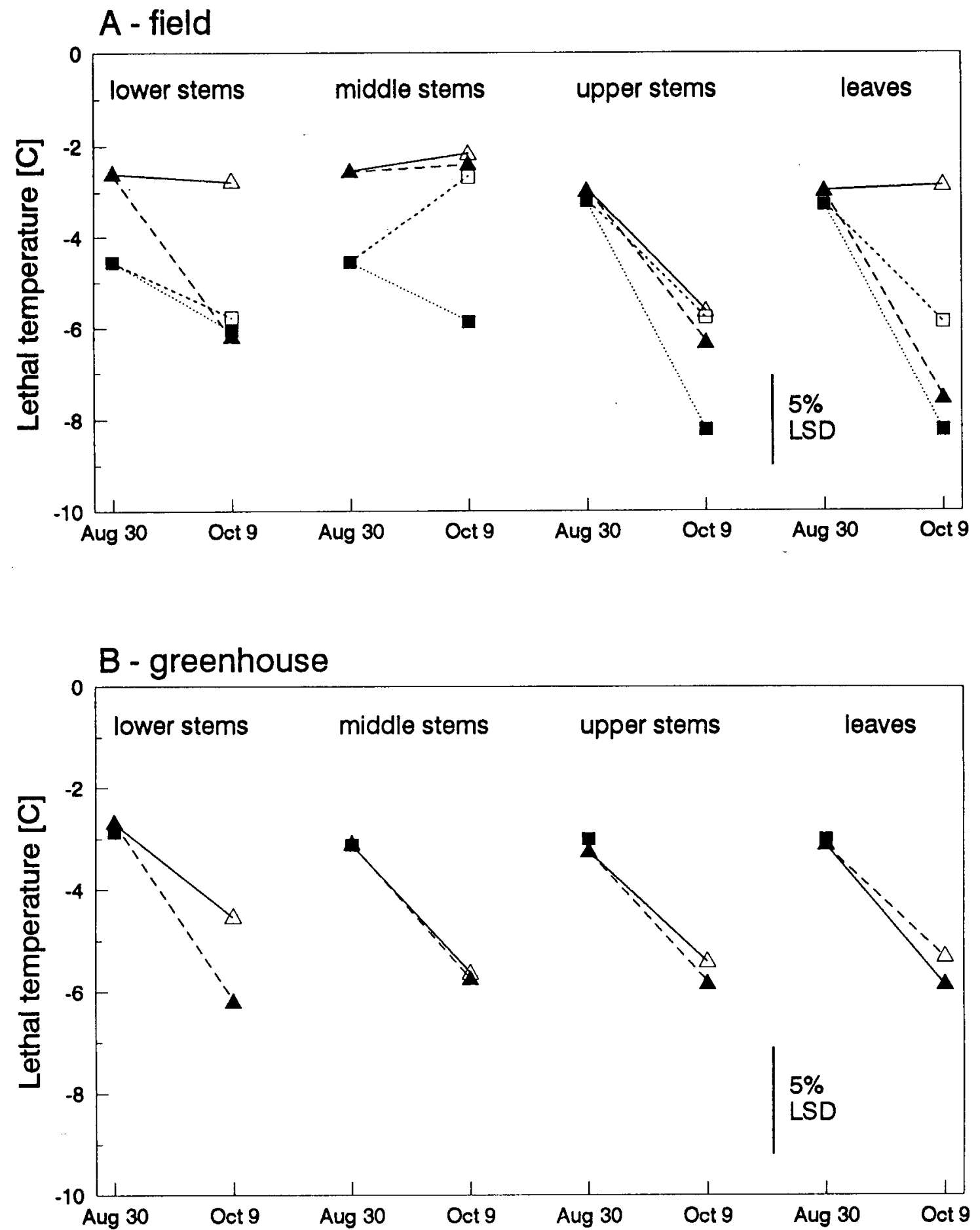

Fig. 2. Lethal temperature for leaves, lower, middle, and upper stems of Rhododendron 'Hinodegiri' plants grown under dry/dry ( $\mathbf{\square})$, dry/wet ( $\square$ ) wet/dry ( $\boldsymbol{\Delta}$ ), and wet/ wet $(\Delta)$ watering regimes in the field (A) and greenhouse (B) study on 30 Aug. and 9 Oct..

least tolerant of more severe water stress under the greenhouse study conditions. Similarly, Norcini and Aldrich (1990) found that the degree of foliar and bark-split injury reduction obtained by applying growth retardants in azaleas was cultivarspecific. The preventive effect of high temperatures on hardening of lower plant parts of azaleas discussed by Alexander and Havis (1980b) may explain differences in lower and middle stem acclimation between cultivars in the field study. Apparently, the same temperatures that prevented early acclimation in $\mathrm{HD}$ and RR when fully supplied with water were permissive for $\mathrm{CB}$ acclimation. In fact, in the latter cultivar, the lower plant parts were even hardier than the upper parts. This obser- vation indicates that delayed acclimation of lower stems compared to upper stems typical for high temperature conditions did not occur in the field-grown CB. However, such a delayed acclimation of lower stems was observed in $\mathrm{CB}$ and $\mathrm{RR}$ in the greenhouse study, where plants were exposed to relatively higher temperatures.

Imposing water stress after 30 Aug. generally increased freeze tolerance of all plant parts regardless of the previous watering regime. In contrast, maintaining high water content of the growing medium during that time prevented acclimation in some cases or even caused deacclimation as in the plants stressed before 30 Aug. Parsons and Li (1979) noted that the water stress-induced hardi- 

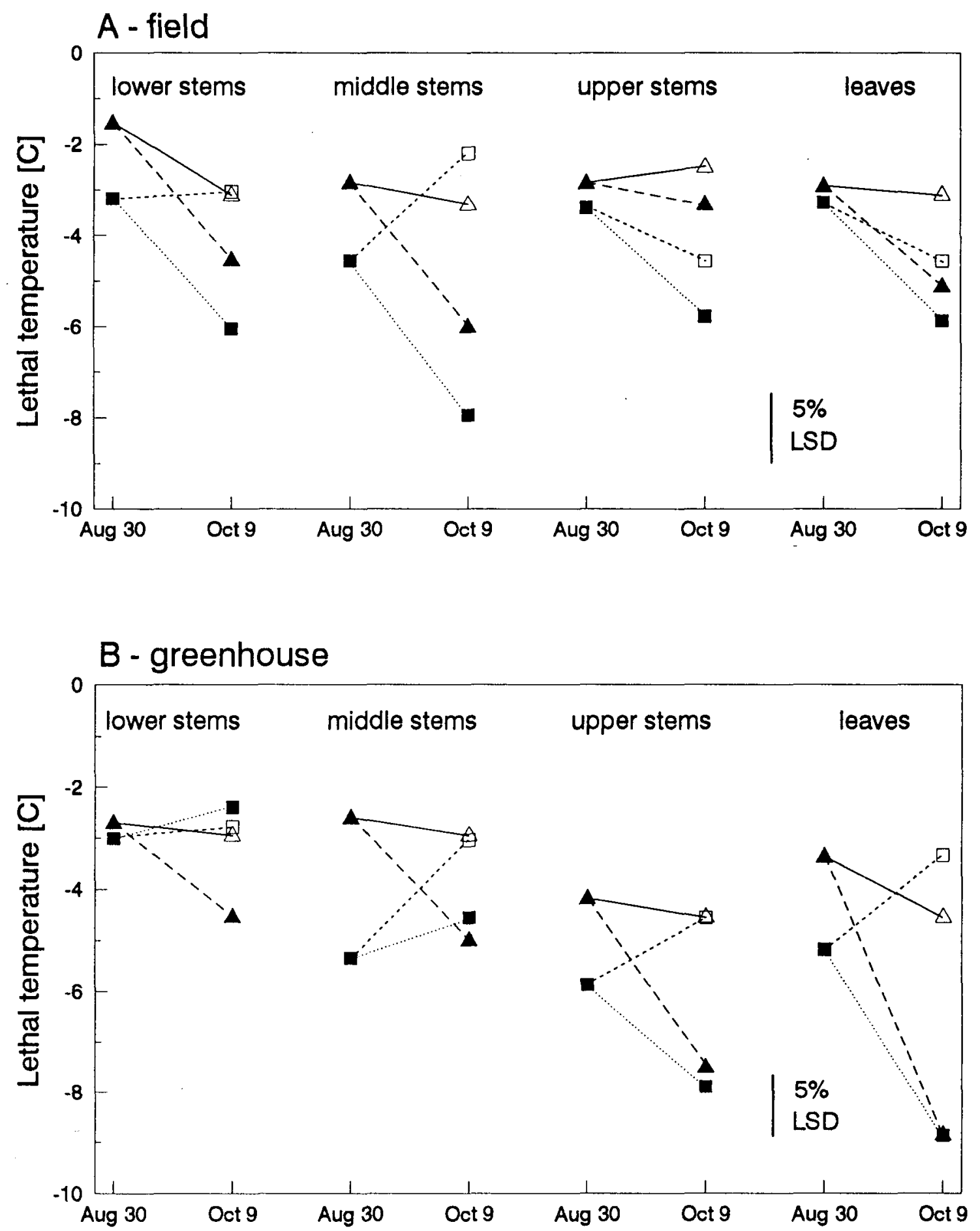

Fig. 3. Lethal temperature for leaves, lower, middle, and upper stems of Rhododendron 'Red Ruffle' plants grown under dry/dry ( $\mathbf{\square})$, dry/wet ( $\square$ ), wet/dry ( $\boldsymbol{\Delta}$ ), and wet/ wet $(\Delta)$ watering regimes in the field $(\mathbf{A})$ and greenhouse $(\mathbf{B})$ study on 30 Aug. and 9 Oct.

ness in red osier dogwood was lost after recovery from the stress if plants were kept under long-day conditions.

Under higher temperature conditions of the greenhouse study, lower stems of $\mathrm{CB}$ and $\mathrm{RR}$ acclimated at the slower rate than the upper plant parts in late summer. This confirms findings of Steponkus and Lanphear (1967), Sakai ( 1968), and Alexander and Havis (1980a) that the induction of freeze tolerance proceeds in phases throughout the plant, with the apices being the first area to acclimate and lower stem area being less hardy than the upper parts in many woody plants. However, under lower temperatures in the field, no such pattern of differential rates of acclimation among various plants was observed. Apparently, high temperatures accompanied by sufficient water supply, as in the greenhouse study, can delay acclimation of lower stems more than the acclimation of the upper plant parts. Creech and Hawley (1960) reported that mulching increased bark split injury of evergreen azaleas, a result they attributed to the delayed acclimation caused by a higher soil moisture content and higher soil temperatures under mulch in the fall.

Reducing water supply provides a feasible mean of promoting acclimation of evergreen azaleas in late summer. In most cases, short-term reduction of water supply was as efficient in increasing freeze tolerance as the long-term reduction through- 
out the entire summer. This allowed for better freeze protection without reducing plant growth.

\section{Literature Cited}

Alexander, L.A. and J.R. Havis. 1980a. Cold acclimation of plant parts in an evergreen and deciduous azalea. HortScience 15:89-90.

Alexander, L.A. and J.R. Havis. 1980b. Root temperature effects on cold acclimation of an evergreen azalea. HortScience 15:90-91.

Anisko, T., D.S. NeSmith, and O.M. Lindstrom. 1994. Application of time-domain reflectometry for measuring water content of organic growing. media in containers. HortScience 29:1511-15 13.

Brooks, A.V. 1974. Disorders of rhododendrons and camellias. Rhododendrons with Magnolias and Camellias 1974:57-62.

Burrows, R. L., L. Waters, Jr., and A.H. Markhart, III. 1989. Cold acclimation of asparagus seedlings subjected to low temperatures or water stress. HortScience 24:812-814.

Chen, P.M., P.H. Li, and M.J. Burke. 1977. Induction of hardiness in stem cortical tissues of Cornus stolonifera Michx. by water stress. Plant Physiol. 59:236-239.

Chen, P., P.H. Li, and C.J. Weiser. 1975. Induction of hardiness in redosier dogwood stems by water stress. HortScience 10:372-374.

Cloutier, Y. and D. Siminovitch. 1982. Correlation between cold-and drought-induced hardiness in winter wheat and rye varieties. Plant Physiol. 69:256-258.

Cook, R. 1978. Bark split in rhododendrons. The Garden 103:280-281. Cox, W. and J. Levitt. 1976. Interrelations between environmental factors and freezing resistance of cabbage leaves. Plant Physiol. 57:553-555.

Creech, J.L. and W. Hawley. 1960. Effects of mulching on growth and winter injury of evergreen azaleas. J. Amer. Soc. Hort. Sci. 75:650-657.
Flint, H.L. 1966. Seasonal hardening in trees and shrubs. Amoldia 26:5760.

Kramer, P.J. 1983. Factors affecting the absorption of water, p. 235-265. In: P.J. Kramer (ed.). Water relations in plants. Academic Press, New York.

McKenzie, J. S., C.J. Weiser, and P.H. Li. 1974. Changes in water relations of Cornus stolonifera during cold acclimation. J. Amer. Soc. Hort. Sci. 99:223-228.

Norcini, J.G. and J.H. Aldrich. 1990. Chemically-induced freeze resistance of azalea. Proc. Fla. State Hort. Soc. 103:196-197.

Parsons, L.R. 1978. Water relations, stomatal behaviour, and root conductivity of red osier dogwood during acclimation to freezing temperatures. Plant Physiol. 62:64-70.

Parsons, L.R. and P.H. Li. 1979. Changes in frost hardiness of stem cortical tissues of Cornus stolonifera Michx. after recovery from water stress. Plant Physiol. 64:351-353.

Sakai, A. 1,968. Frost damage on basal stems of young trees. Contr. Inst. Low Temp. Sci. B 15:1-14.

SAS Institute. 1985. SAS user's guide. SAS Institute, Cary, N.C. p. 575606.

Steponkus, P.L. and F.O. Lanphear. 1967. Light stimulation of cold acclimation: Production of a translocatable promoter. Plant Physiol. 42:1673-1679.

Thomas, H. and A.R. James. 1993. Freezing tolerance and solute changes in contrasting genotypes of Lolium perenne $\mathrm{L}$. acclimated to cold and drought. Ann. Bet. 72:249-254.

von Firks, H.A. and T. Verwijst. 1993. Plant viability as a function of temperature stress. Plant Physiol. 103:125-1 30.

Yelenosky, G. 1979. Water-stress-induced cold hardening of young citrus trees. J. Amer. Soc. Hort. Sci. 104:270-273. 